\title{
Increased Depression-Like Behaviors in Corticotropin- Releasing Factor Receptor-2-Deficient Mice: Sexually Dichotomous Responses
}

\author{
Tracy L. Bale and Wylie W. Vale \\ Clayton Foundation Laboratories for Peptide Biology, The Salk Institute, La Jolla, California 92037
}

\begin{abstract}
Depressive disorders affect nearly 19 million American adults, making depression and the susceptibility for developing depression a critical focus of mental health research today. Females are twice as likely to develop depression as males. Stress is a known risk factor for developing depression, and recent hypotheses suggest an involvement of an overactive stress axis. As mediators of the stress response, corticotropin-releasing factor (CRF) and its receptors (CRFR1 and CRFR2) have been implicated in the propensity for developing stress-related mood disorders. Mice deficient in CRFR2 display increased anxiety-like behaviors and a hypersensitive stress response. As a possible animal model of depression, these mice were tested for depression-like behaviors in the forced swim test. Comparisons were made between wild-type and mutant animals, as well as between sexes. Male and female CRFR2-mutant mice showed increased immobility as an indicator of depression compared with wild-type mice of the same sex. In addition, mutant and wild-type female mice demonstrated increased immobile time compared with males of the same genotype. Treatment of CRFR2-deficient mice with the CRFR1 antagonist antalarmin decreased immobile time and increased swim time in both sexes. We found a significant effect of sex for both time spent immobile and swimming after antalarmin treatment. Because differences in behaviors in the forced swim test are good indicators of serotonergic and catecholaminergic involvement, our results may reveal an interaction of CRF pathways with other known antidepressant systems and may also support an involvement of CRF receptors in the development of depression such that elevated CRFR1 activity, in the absence of CRFR2, increases depression-like behaviors.
\end{abstract}

Key words: CRF; CRF receptors; depression; antalarmin; forced swim test; mice

\section{Introduction}

Depressive disorders affect nearly 19 million American adults and are thought to be the most prevalent form of mental illness. Evidence from research and clinical investigations demonstrates that depression encompasses a profound neurocircuitry failure. The brain regions involved in this dysregulation may include the hypothalamus, hippocampus, amygdala, and striatum (Liotti and Mayberg, 2001; Nestler et al., 2002). These nuclei are important regulators in endocrine control of behaviors symptomatic of depression, such as eating, sleeping, circadian rhythm, stress response, learning and memory, and pleasure seeking. Depressed patients present with a great variability of their symptoms, as well as in their response to drug treatment, thus emphasizing the complex nature of this illness.

Strong evidence links stress, and the sensitivity of the individual to stressful encounters, to the development of depression. The stress response is essential for adaptation, maintenance of ho-

Received Nov. 18, 2002; revised Feb. 28; accepted March 21, 2003.

This work was supported by National Institutes of Health Project Grant DK 26741, by the Robert J. and Helen C. Kleberg Foundation, by the Adler Foundation, and by the Foundation for Research. W.W.V. is a Foundation for Research senior investigator. We thank K. Anderson and K. Creehan for technical support, S. Guerra for help with this manuscript, and $\mathrm{G}$. Chrousos for the generous gift of antalarmin.

Correspondence should be addressed to Dr. Tracy L. Bale, Clayton Foundation for Peptide Biology, The Salk Institute, 10010 North Torrey Pines Road, La Jolla, CA 92037. E-mail: bale@salk.edu.

Copyright @ 2003 Society for Neuroscience $\quad 0270-6474 / 03 / 235295-07 \$ 15.00 / 0$ meostasis, and survival. However, chronic stress can accelerate disease processes, cause neural degeneration, and lead to depression or other mood disorders (Nestler et al., 2002). A key factor in the response to stress is the neuropeptide corticotropin-releasing factor (CRF) (Vale et al., 1981). CRF and its receptors (CRFR1 and CRFR2) are important regulators of the hypothalamicpituitary-adrenal (HPA) axis. A large body of evidence now ties CRF to the development of depression (Nemeroff, 1988, 1992; Arborelius et al., 1999; Holsboer, 1999; Reul and Holsboer, 2002). Clinical studies have found increased CRF and decreased CRF receptors in postmortem examination of suicide victims. In addition, excessive activation of the HPA axis has been reported in more than one-half of patients with depression, and these symptoms have been corrected during antidepressant treatment (Holsboer, 1999). Whereas CRF stimulates the HPA axis in response to stress and plays a key role in activation of anxiety behaviors via activation of CRFR1, other CRF family members, such as urocortinI (UcnI), UcnII, and UcnIII, may act to decelerate the stress response via activation of CRFR2 (Bale et al., 2000, 2002; Coste et al., 2000; Valdez et al., 2002). Localization of CRF receptors within brain regions thought to be involved in the neural circuitry of depression also supports an involvement of CRF pathways in the pathogenesis of this disease (Chalmers et al., 1995). It is clear that the delicate balance of the CRF system is critical for maintenance of mental and physical soundness. 
The increased susceptibility of females to depression has been well documented, although the underlying mechanisms remain insufficiently studied and virtually unknown (Kornstein, 1997; Kendler, 1998; Frackiewicz et al., 2000). Differences in neuroendocrine pathways or sexually dimorphic brain regions may be key factors influencing sensitivity. The CRF system and stress have not been well examined in relation to gender differences in the development of depression but may be key factors influencing increased female susceptibility (Young, 1998). CRFR2-deficient mice have been reported previously to display a hypersensitive HPA axis, anxiogenic-like behavior, and elevated levels of CRF and UcnI (Bale et al., 2000). As a possible mouse model of depression, male and female CRFR2-deficient mice were examined for depression-like behaviors. To determine the possible involvement of CRFR1 overactivity in the absence of CRFR2, the nonpeptide CRFR1 antagonist antalarmin was administered before testing. Previous studies have demonstrated an antidepressant action of antalarmin in the forced swim test (Griebel et al., 2002). Our studies reveal an involvement of CRF receptors in the development of depression and distinct behavioral sex differences in response to CRFR1 antagonist treatment.

\section{Materials and Methods}

Animals. CRFR2-deficient mice were constructed as reported previously (Bale et al., 2000). Mice were housed under controlled conditions of $12 \mathrm{hr}$ light/dark (lights on at 6:00 A.M.) with access to food and water ad libitum. All procedures were approved by the Institutional Animal Care and Use Committee of the Salk Institute.

Forced swim test. To measure the depression-like behaviors of mice deficient for CRFR2, littermate male and female CRFR2-mutant and wild-type mice $(n=10)$ were tested in a modified version of the forced swim test. The test was modified by increasing the depth of the water in the cylinder to $15 \mathrm{~cm}$ above the bottom of the cylinder (Lucki, 1997; Cryan et al., 2002). All animals were placed in the cylinder for a preswim for $5 \mathrm{~min}$ on day 1 and then monitored during a $5 \mathrm{~min}$ test $24 \mathrm{hr}$ after the preswim (Crawley, 2000). The time spent swimming, climbing, and immobile were determined by an investigator blind to genotype and treatment. Immobility was defined as time spent still or only using righting movements to remain afloat. Swimming was defined as any movement horizontal in nature that involved at least two limbs. Climbing was defined as any vertical movement in which the bottom of the front paws touched the sides of the cylinder.

Effects of antalarmin on depression-like behaviors. To determine whether antagonism of CRFR1 could reverse the increased depressionlike behaviors detected in the CRFR2-mutant mice, in separate experiments, male and female CRFR2-deficient mice $(n=10)$ were injected with either antalarmin ( $7.5 \mathrm{mg} / \mathrm{kg}$, i.p.) or vehicle (100 $\mu$ l volume, i.p.) 1 $\mathrm{hr}$ before the test swim. As noted above, the preswim and test were $5 \mathrm{~min}$ each. Scoring was again performed by an investigator blind to treatment. To examine the prolonged effect of antalarmin treatment on depressionlike behaviors, because many antidepressants require longer exposures, mice were tested again either 24 or $72 \mathrm{hr}$ after treatment in a second $5 \mathrm{~min}$ test swim such that each animal was tested only two times $(n=5)$. Behaviors were scored as described above. For comparison of male and female responses to antalarmin treatment for all behaviors, data were analyzed by two-way ANOVA.

Drug. Antalarmin was generously supplied by Dr. George Chrousos (National Institute of Child Health and Human Development, National Institutes of Health, Bethesda, MD) (Webster et al., 1996; Habib et al., 2000). The drug was dissolved in DMSO at $9 \mathrm{mg} / \mathrm{ml}$ and diluted in $0.9 \%$ saline before intraperitoneal injection. Vehicle was the same concentration of DMSO in $0.9 \%$ saline.

Statistics. Results for all tests were averaged, and statistics were done using Statview (SAS Institute, Cary, NC). A two-way ANOVA was used to analyze the effects of sex and genotype or effects of sex and treatment on the depression-like behaviors measured to compare all groups. Significant main effects were probed using Fisher's PLSD tests. Those effects

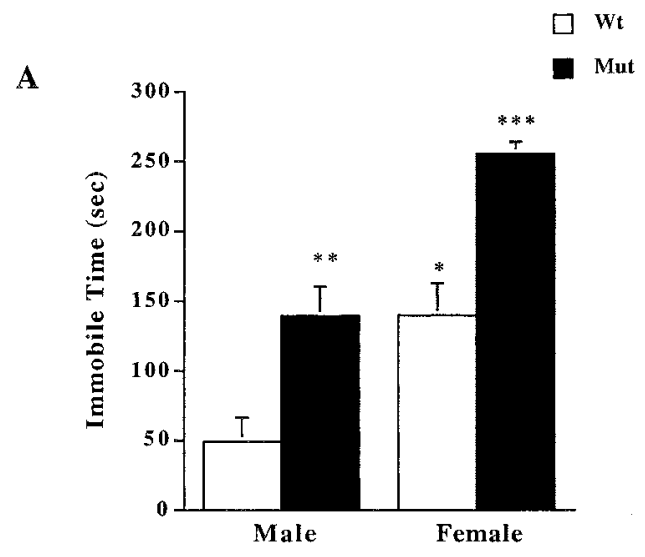

B

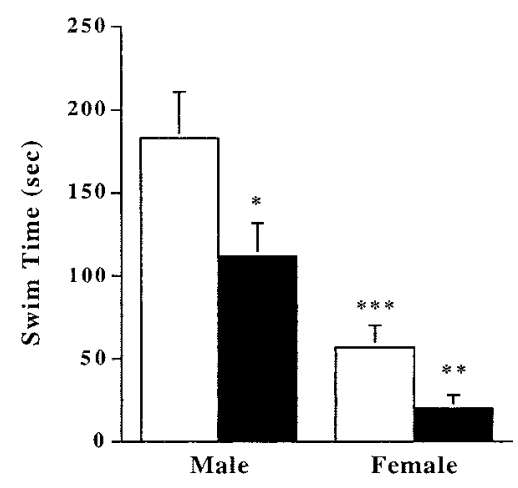

C

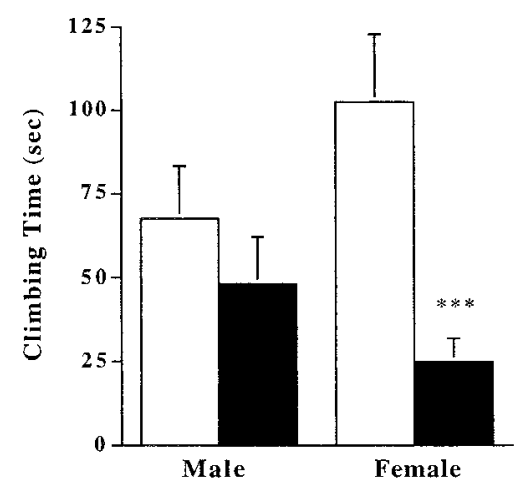

Figure 1. Measurement of depression-like behaviors in forced swim test. $A$, Both male and female mutant (Mut) mice showed increased immobile time during 5 min forced swim compared with wild-type (Wt) mice $(n=10)$. Overall, females showed significantly greater immobile time compared with their respective males of the same genotype. ${ }^{*} p<0.05$ compared with wild-type males; ${ }^{* *} p<0.01$ compared with wild-type males; ${ }^{* * *} p<0.001$ compared with wild-type females and male mutant mice; ANOVA and Fisher's post hoc test. $B$, Both male and female mutant mice demonstrated decreased swim time compared with wild-type littermates $(n=10) .{ }^{*} p<0.05$ compared with wild-type males; ${ }^{* *} p<0.01$ compared with wild-type females; ${ }^{* * *} p<0.001$ compared with wild-type males; ANOVA and Fisher's post hoc test. C, Female mice deficient for CRFR2 spent significantly less time climbing during the forced swim test compared with female wild-type littermates; ${ }^{* * *} p<0.001$; ANOVA and Fisher's post hoc test.

that were determined to have a significant interaction were further probed using a Tukey-Kramer post hoc test for significance.

\section{Results}

Depression-like behaviors in modified forced swim test

To examine depression-like behaviors in mice deficient for CRFR2 compared with wild-type littermates, male and female mice were tested in the forced swim test. The tests revealed a 
significant increase in immobility time in both male and female CRFR2-mutant mice compared with their wild-type littermates (Fig. 1A). Significant differences were detected by two-way ANOVA for both sex and genotype effects, $\left(F_{(1,1,36)}=30.66, p<\right.$ 0.0001 for sex; $F_{(1,1,36)}=30.71, p<0.0001$ for genotype). Wildtype and mutant female mice showed significantly more immobile time than their corresponding male mice did. Female and male mutant mice showed a significant decrease in time spent swimming during the test compared with their wild-type littermates (Fig. $1 B)\left(F_{(1,1,36)}=40.28, p<0.0001\right.$ for sex; $F_{(1,1,36)}=$ $7.90, p=0.008$ for genotype). Female mutant mice also showed a significant decrease in time spent climbing during the test compared with their female wild-type littermates (Fig. 1C) $\left(F_{(1,1,36)}=\right.$ $0.18, p=0.68$ for sex; $F_{(1,1,36)}=12.91, p=0.001$ for genotype $)$. However, no difference in time spent climbing was found between male wild-type and mutant mice. There was a significant interaction of sex and genotype for time spent climbing $(p=$ 0.03). A Tukey-Kramer post hoc test was performed to determine the extent of the interaction. A significant difference was detected between female wild-type and mutant mice for time spent climbing (critical difference of 83.5/40.7).

\section{Response to CRFR1 antagonist (antalarmin) treatment}

To determine whether increased CRFR1 activity in the absence of CRFR2 was the possible cause of the increased depression-like behaviors in CRFR2-deficient mice, a CRFR1 small-molecule antagonist, antalarmin, was administered to CRFR2-mutant mice before testing in the forced swim test. Previous reports have demonstrated a decrease in immobile time in the forced swim test after antalarmin treatment (Griebel et al., 2002), as well as decreases in depression in humans in response to other CRFR1 nonpeptide antagonists (Zobel et al., 2000).

\section{Females}

Results revealed a significant decrease in immobile time (Fig. 2A) and an increase in swimming (Fig. 2B) and climbing (Fig. 2C) times in female CRFR2-deficient mice pretreated with antalarmin. The decrease in immobility was detectable $1 \mathrm{hr}$ after treatment in female mutant mice compared with vehicle-treated mutant females and remained significantly decreased 24 and $72 \mathrm{hr}$ after treatment (Fig. 2A). A two-way ANOVA showed a significant effect of both sex and treatment $1 \mathrm{hr}$ after treatment $\left(F_{(1,1,36)}\right.$ $=4.82, p=0.03$ for sex; $F=81.1, p<0.0001$ for treatment). No significant interaction was detected between sex and treatment for time spent immobile at the $1 \mathrm{hr}$ time point. Antalarmin pretreatment of CRFR2-mutant female mice decreased immobile time by $1 \mathrm{hr}$ to levels slightly lower than untreated wild-type female immobile time (Fig. $1 A$ ). The effect of treatment was significant at the $24 \mathrm{hr}$ time point $\left(F_{(1,1,15)}=75.39, p<0.0001\right)$. The effect of both sex and treatment was significant $72 \mathrm{hr}$ after treatment $\left(F_{(1,1,15)}=8.37, p=0.01\right.$ for sex; $F=13.45, p=0.004$ for treatment), with no significant interaction between sex and treatment.

The increase in swimming was detectable $1 \mathrm{hr}$ after treatment in female mutant mice compared with vehicle-treated mutant females and remained significantly increased 24 and $72 \mathrm{hr}$ after treatment (Fig. $2 \mathrm{~B}$ ). A two-way ANOVA showed a significant effect of both sex and treatment $1 \mathrm{hr}$ after treatment $\left(F_{(1,1,36)}=\right.$ 4.63, $p=0.04$ for sex; $F=19.0, p<0.0001$ for treatment). No significant interaction was detected between sex and treatment for time spent swimming at the $1 \mathrm{hr}$ time point. The effect of treatment, but not sex, was significant at the $24 \mathrm{hr}$ time point $\left(F_{(1,1,15)}=26.86, p=0.0006\right)$.
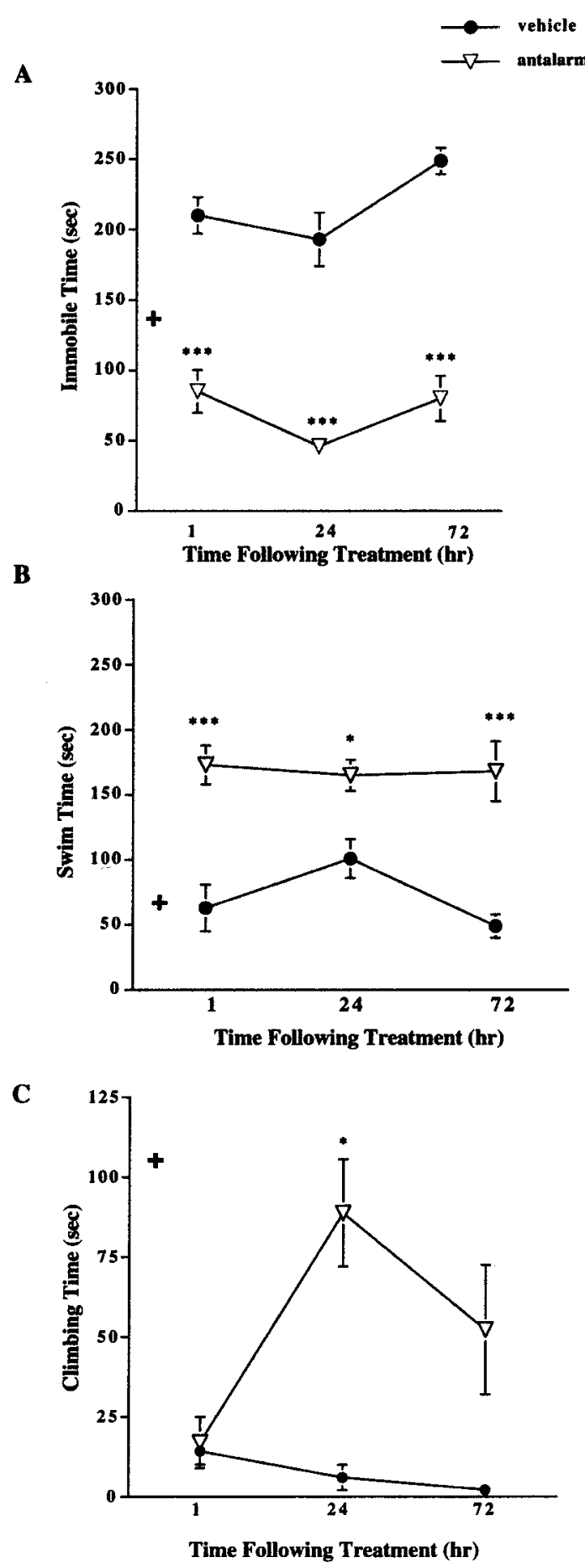

Figure 2. Forced swim test results after pretreatment with antalarmin in female CRFR2deficient mice. $A$, Female mutant mice treated with antalarmin $(7.5 \mathrm{mg} / \mathrm{kg}) 1 \mathrm{hr}$ before testing showed decreased immobile time compared with vehicle-treated mutant mice $(n=10)$. ${ }^{* * *} p<0.001$. This effect remained evident $24(n=5)$ and $72(n=5) \mathrm{hr}$ after treatment. ${ }^{* * *} p<0.001$; ANOVA and Fisher's post hoc test. + indicates basal wild-type female immobile levels for comparison. $B$, Female mutant mice treated with antalarmin displayed increased swim time compared with vehicle-treated mutant females $1(n=10), 24(n=5)$, and 72 $(n=5)$ hr after treatment. ${ }^{*} p<0.05 ;{ }^{* * *} p<0.001$; ANOVA and Fisher's post hoc test. + indicates basal wild-type female swim levels for comparison. C, Female mutant mice treated with antalarmin showed increased climbing time $24 \mathrm{hr}(n=5)$ after treatment compared with vehicle-treated females. ${ }^{*} p<0.05$. No difference was detected in climbing time $1 \mathrm{hr}$ after treatment $(n=10)$; ANOVA and Fisher's post hoc test. + indicates basal wild-type female climbing levels for comparison. 
No difference in climbing time was detected $1 \mathrm{hr}$ after antalarmin treatment. In females, a significant increase in time spent climbing was detected $24 \mathrm{hr}$ after antalarmin administration and was still detectable $72 \mathrm{hr}$ after treatment (Fig. 2C). Time spent climbing for CRFR2-deficient females $24 \mathrm{hr}$ after antalarmin treatment was similar to that shown for untreated wild-type females (Fig. 1C). A significant effect of both sex and treatment was found at the $24 \mathrm{hr}$ time point $\left(F_{(1,1,15)}=5.63, p=0.04\right.$ for sex; $F=12.18, p=0.007)$.

Males

Results revealed a significant decrease in immobile time in male CRFR2-deficient mice 1 and $24 \mathrm{hr}$ after antalarmin treatment compared with vehicle-treated male mutant mice (Fig. $3 A$ ). The level of immobility detected in the antalarmin-treated mutant male mice was similar to that found in untreated wild-type male mice (Fig. 1A). Comparison of males and females by ANOVA for immobile time after treatment is described above.

Results revealed a significant increase in swim time in male CRFR2-deficient mice 1 and $24 \mathrm{hr}$ after antalarmin treatment compared with vehicle-treated male mutant mice (Fig. $3 B$ ). The increased level of swimming detected in the antalarmin-treated mutant male mice was similar to that found in untreated wildtype male mice (Fig. $1 B$ ). Comparison of males and females for swimming time after treatment is described above.

A significant increase in time spent climbing was detected in male mutant mice $24 \mathrm{hr}$ after treatment with antalarmin (Fig. 3C). This effect was not significantly different from vehicle-treated males 1 or $72 \mathrm{hr}$ after treatment. Comparison of males and females for climbing time after treatment is described above.

\section{Discussion}

Depression is the most common form of mental illness in America (Nestler et al., 2002). The mechanisms underlying this disease are relatively unknown, as are the reasons for the inconsistencies in patient responsiveness to antidepressant treatment. Stress and the sensitivity to stress appear to be risk factors. Evidence links CRF and an overactive HPA axis to a high risk for development of depression (Nemeroff, 1988; Curtis and Valentino, 1994; Arborelius et al., 1999; Heim and Nemeroff, 1999; Sauvage and Steckler, 2001; Reul and Holsboer, 2002). Mice deficient in CRFR2 have been shown to display a hypersensitive HPA axis, as well as anxiogenic-like behaviors (Bale et al., 2000; Coste et al., 2000; Kishimoto et al., 2000). Previous hypotheses have suggested that this phenotype of CRFR2-deficient mice may be attributable to unimpeded CRFR1 activity in the absence of CRFR2 (Bale et al., 2000, 2002). These mice provide a good model to examine the effects of prolonged stress sensitivity and increased anxiety on the development of depression. Normal mice are typically not useful models for the study of depression because the development of most depressions likely requires a genetic vulnerability (Nestler et al., 2002).

In these studies, male and female CRFR2-deficient mice showed increased depression-like behaviors in the forced swim test. Female mutant mice demonstrated both increased immobility, as well as decreased swimming and climbing time, compared with their wild-type female littermates. Male mutant mice also showed a significant increase in immobile time and a decrease in swim time, but no difference was detected in time spent climbing compared with wild-type male mice. These distinct differences in depression behaviors suggest potential roles for CRF receptors in the development and presentation of depression. Treatment with the CRFR1 small-molecule antagonist antalarmin decreased im-

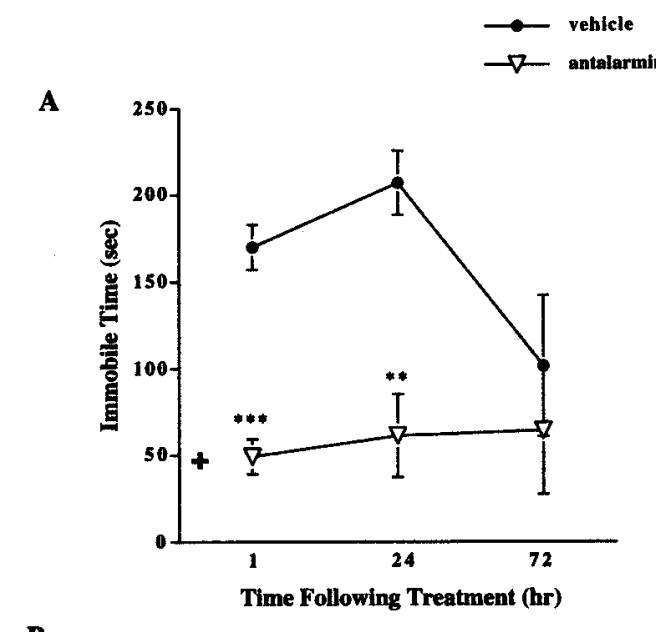

$\mathbf{B}$

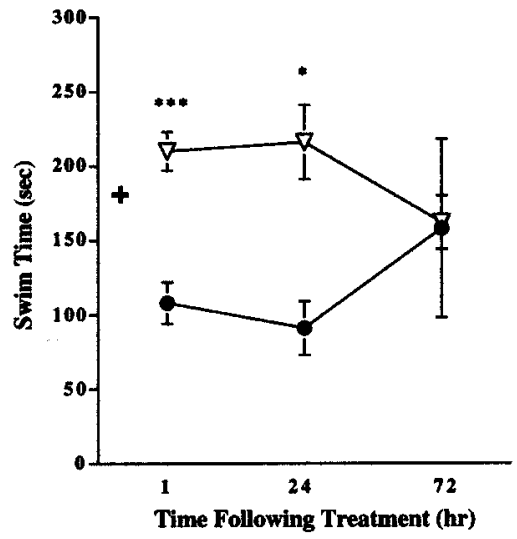

C

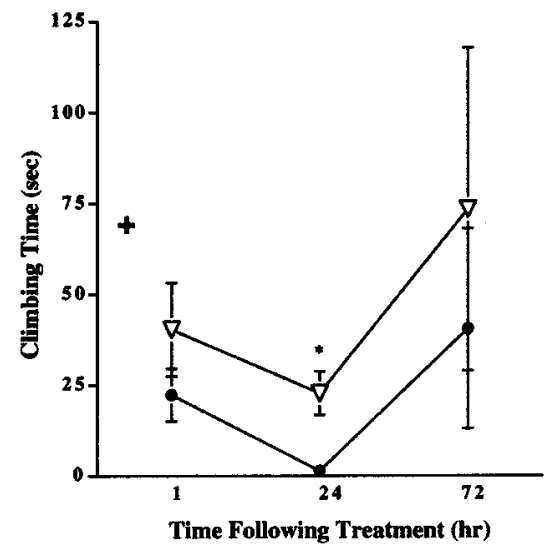

Figure 3. Forced swim test results after pretreatment with antalarmin in male CRFR2deficient mice. A, Male mutant mice treated with antalarmin $(7.5 \mathrm{mg} / \mathrm{kg}) 1 \mathrm{hr}$ before testing showed decreased immobile time compared with vehicle-treated mutant mice $(n=10)$. ${ }^{* * *} p<0.001$. This effect remained evident $24 \mathrm{hr}(n=5)$ after treatment. ${ }^{* *} p<0.01$. No difference in immobile time was detected $72 \mathrm{hr}(n=5)$ after treatment; ANOVA and Fisher's posthoc test. + indicates basal wild-type male immobile levels for comparison. B, Male mutant mice treated with antalarmin $1 \mathrm{hr}$ before testing showed increased swim time compared with vehicle-treated mutant mice $(n=10)$. ${ }^{* *} p<0.001$. This effect remained evident $24 \mathrm{hr}$ $(n=5)$ after treatment. ${ }^{*} p<0.05$. No difference in swim time was detected $72 \mathrm{hr}(n=5)$ after treatment; ANOVA and Fisher's post hoc test. + indicates basal wild-type male swim levels for comparison. C, Male mutant mice treated with antalarmin showed increased climbing time 24 $\mathrm{hr}(n=5)$ after treatment compared with vehicle-treated males. ${ }^{*} p<0.05$. No difference was detected between antalarmin and vehicle-treated males in climbing time $1 \mathrm{hr}(n=10)$ or $72 \mathrm{hr}$ $(n=5)$ after treatment; ANOVA and Fisher's post hoc test. + indicates basal wild-type male climbing levels for comparison. 
mobile time and increased swimming and climbing time in both CRFR2-deficient male and female mice. These results support the prevailing hypothesis that increased CRFR1 activity results in increased susceptibility for the development of depression, because previous studies have demonstrated an involvement of unimpeded CRFR1 activity or increased production of CRF with the development of anxiety-like or depression-like behaviors in rodents and humans (Stenzel-Poore et al., 1994; Arborelius et al., 1999; Holsboer, 1999; Zobel et al., 2000; Griebel et al., 2002). We previously reported increased CRF levels in the central nucleus of the amygdala and increased UcnI levels in the Edinger Westphal nucleus in CRFR2-deficient mice (Bale et al., 2000). Elevated ligand levels acting at CRFR1 may be influencing neurotransmitter release from brain regions important for normal responses to stress and homeostatic maintenance. Dysregulation of this pathway may then lead to a proclivity for developing depression-like behaviors, as seen in the CRFR2-mutant mice.

The time course and sexually dichotomous response of antalarmin treatment detected in the CRFR2 mice may provide clues as to the neurotransmitters involved in the onset of depression. The modified forced swim test for depression has been demonstrated to be a good model of depression in rodents and is responsive to various antidepressant treatments (Detke et al., 1997; Lucki, 1997; Cryan et al., 2002). In this test, antidepressant treatments decrease immobile time, by either increasing swim time and/or increasing climbing time. Studies have categorized these effects as specific to different neurotransmitter pathways, such that catecholaminergic agents may decrease immobility by increasing climbing, whereas serotonergic agents may decrease immobile time by increasing swimming (Lucki, 1997). On the basis of these studies, results in the CRFR2-deficient mice may indicate that the response to antalarmin on decreasing immobility and increasing swimming in both females and males may be attributable to effects on these neurotransmitter pathways.

Electrophysiological, biochemical, and anatomical localization studies have shown direct input and potent activation of CRF fibers in the dorsal raphe nucleus (DR) (Price et al., 1998; Kirby et al., 2000; Price and Lucki, 2001; Valentino et al., 2001). CRF has been shown to affect 5-HT release to both the striatum and lateral septum, as well as to directly alter DR neuronal activity, whereas low doses were shown to inhibit 5-HT release, and high doses were shown to either increase or have no effect (Valentino et al., 2001). These results may be attributable to the heterogeneity of the DR or to the specific CRF receptor being activated (Valentino et al., 2001; Hammack et al., 2002). Both CRFR1 and CRFR2 have been detected in the DR and may have opposing roles for 5-HT release. Because CRF has a 10-fold higher affinity for CRFR1 than CRFR2, low doses of CRF in the DR may preferentially activate CRFR1, whereas higher doses could potentially stimulate neurons expressing both receptors. Thus, one may hypothesize then that activation of CRFR1 inhibits 5-HT release, whereas activation of CRFR2 may augment its release (Valentino et al., 2001; Hammack et al., 2002). Certainly, a growing body of evidence now supports this hypothesis and has demonstrated CRF receptorspecific effects on 5-HT fibers. The CRFR1 antagonist antalarmin has been shown previously to block the inhibitory effects of CRF by increasing 5-HT release (Kirby et al., 2000). Additionally, CRFR1deficient mice demonstrate enhanced hippocampal 5-HT neurotransmission (Penalva et al., 2002). These results support those shown previously that antagonism of CRFR1 decreases depressionlike behaviors in rodents (Griebel et al., 2002), as well as in humans
(Zobel et al., 2000). Our results add to this hypothesis by suggesting that, in the absence of CRFR2, CRFR1 tone predominates and may affect 5-HT release and increase susceptibility to the development of depression-like behaviors. Antalarmin treatment increased time spent swimming for the CRFR2-mutant mice, indicating that this antagonist may be affecting serotonergic pathways.

In addition to 5-HT involvement, catecholamines have also been associated with the development of depression (Nestler et al., 2002). CRF interactions with dopamine and norepinephrine neurotransmission have been demonstrated and may involve direct or indirect actions on cell bodies in the locus ceruleus (LC) or ventral tegmental area (VTA) (Melia and Duman, 1991; Swiergiel et al., 1992; Curtis and Valentino, 1994; Lechner et al., 1997; Kawahara et al., 2000). CRFR1 has been detected in both the VTA (Sauvage and Steckler, 2001) and in the LC (Valentino, 1989; Valentino et al., 1992). Antagonism of CRFR1 has been demonstrated to inhibit discharge from the LC (Curtis and Valentino, 1994; Curtis et al., 1994, 1997). Results from our studies show a response of CRFR2-deficient male and female mice to antalarmin treatment with respect to climbing behavior in the forced swim test. Increased climbing behavior has been associated with changes in catecholaminergic neurotransmission (Cryan et al., 2002) and therefore may indicate possible involvement of the CRF system with catecholaminergic pathways. Certainly, the delayed response detected in the mutant mice may be indicative of downstream interactions rather than primary targets.

Depression is twice as common in females as it is in males. The basis for this increased susceptibility is unknown but may involve sex differences in hormonal or stress response pathways (Young, 1998) or sexually dimorphic brain regions important in the neurobiology of depression (Kornstein, 1997; Kendler, 1998; Frackiewicz et al., 2000). In deciphering the mechanisms involved in these sex differences, we examined both male and female mice for depression-like behaviors. Results from our analyses using a two-way ANOVA indicate a significant effect of sex, independent of genotype, for time spent immobile and time spent swimming for both wild-type and CRFR2-mutant mice. Our analysis also showed an interaction of sex and genotype for time spent climbing. Probing of this interaction showed that only females had a significant difference in time spent climbing, with the mutant females climbing significantly less than the wild-type females. These results support a sex difference in susceptibility to depression and depression-like behaviors in mice and may suggest that mice are good animal models in which sex differences could be further studied.

Antalarmin treatment of both males and females demonstrated a rapid decrease in immobile time after treatment. However, the duration of action was longer in females. Results from ANOVA comparison of males and females found a significant effect of sex, independent of treatment, for time spent immobile and time spent swimming after antalarmin treatment, indicating that females may be more responsive to antagonism of CRFR1 over time. However, unexplainable changes in the behaviors of the male control group at $72 \mathrm{hr}$ may have affected the outcome of statistical comparisons. Although neither sex showed a significant increase in climbing 1 $\mathrm{hr}$ after treatment, there was a significant effect of sex at the 24 hr time point, and only females showed a significant change by $72 \mathrm{hr}$, providing additional evidence of possible CRF-stress pathway involvement in the increased susceptibility of females for depression. These results provide support for more detailed examination of stress responsivity as an indicator of susceptibility to depression, especially in females. 
In summary, our results have identified a significant increase in depression-like behaviors in CRFR2-deficient mice. Additionally, we demonstrated sexually dichotomous sensitivity, in terms of duration of action, to antalarmin treatment of depression-like behaviors in CRFR2-mutant males and females. These results may establish possible interactions of CRF in the development and increased sensitivity of females for depression. Elevated CRF and UcnI levels acting on CRFR1 in these mice may be contributing to the increased depressionlike behavioral responses detected. These results also suggest that mice may be good animal models for examining sex differences in depression. Additional studies examining the involvement of CRF family members, as well as distinct neurotransmitter systems, will provide necessary information about the genetic and neurobiological basis relating stress and depression and the increased risk for females.

\section{References}

Arborelius L, Owens MJ, Plotsky PM, Nemeroff CB (1999) The role of corticotropin-releasing factor in depression and anxiety disorders. J Endocrinol 160:1-12.

Bale TL, Contarino A, Smith GW, Chan R, Gold LH, Sawchenko PE, Koob GF, Vale WW, Lee KF (2000) Mice deficient for corticotropin-releasing hormone receptor-2 display anxiety-like behaviour and are hypersensitive to stress. Nat Genet 24:410-414.

Bale TL, Picetti R, Contarino A, Koob GF, Vale WW, Lee KF (2002) Mice deficient for both corticotropin-releasing factor receptor 1 (CRFR1) and CRFR2 have an impaired stress response and display sexually dichotomous anxiety-like behavior. J Neurosci 22:193-199.

Chalmers DT, Lovenberg TW, De Souza EB (1995) Localization of novel corticotropin-releasing factor receptor (CRF2) mRNA expression to specific subcortical nuclei in rat brain: comparison with CRF1 receptor mRNA expression. J Neurosci 15:6340-6350.

Coste SC, Kesterson RA, Heldwein KA, Stevens SL, Heard AD, Hollis JH, Murray SE, Hill JK, Pantely GA, Hohimer AR, Hatton DC, Phillips TJ, Finn DA, Low MJ, Rittenberg MB, Stenzel P, Stenzel-Poore MP (2000) Abnormal adaptations to stress and impaired cardiovascular function in mice lacking corticotropin-releasing hormone receptor-2. Nat Genet 24:403-409.

Crawley J (2000) What's wrong with my mouse: behavioral phenotyping of transgenic and knockout mice, pp 192-194. New York: Wiley-Liss.

Cryan JF, Markou A, Lucki I (2002) Assessing antidepressant activity in rodents: recent developments and future needs. Trends Pharmacol Sci 23:238-245.

Curtis AL, Valentino RJ (1994) Corticotropin-releasing factor neurotransmission in locus coeruleus: a possible site of antidepressant action. Brain Res Bull 35:581-587.

Curtis AL, Grigoriadis DE, Page ME, Rivier J, Valentino RJ (1994) Pharmacological comparison of two corticotropin-releasing factor antagonists: in vivo and in vitro studies. J Pharmacol Exp Ther 268:359-365.

Curtis AL, Lechner SM, Pavcovich LA, Valentino RJ (1997) Activation of the locus coeruleus noradrenergic system by intracoerulear microinfusion of corticotropin-releasing factor: effects on discharge rate, cortical norepinephrine levels and cortical electroencephalographic activity. J Pharmacol Exp Ther 281:163-172.

Detke MJ, Johnson J, Lucki I (1997) Acute and chronic antidepressant drug treatment in the rat forced swimming test model of depression. Exp Clin Psychopharmacol 5:107-112.

Frackiewicz EJ, Sramek JJ, Cutler NR (2000) Gender differences in depression and antidepressant pharmacokinetics and adverse events. Ann Pharmacother 34:80-88.

Griebel G, Simiand J, Steinberg R, Jung M, Gully D, Roger P, Geslin M, ScattonB,MaffrandJP,SoubrieP (2002) 4-(2-Chloro-4-methoxy-5-methylphenyl)- $N$-[(1S)-2-cyclopropyl-1-(3-fluoro-4-methylphenyl)ethyl]5-methyl- $N$-(2-propynyl)-1, 3-thiazol-2-amine hydrochloride (SSR125543A), a potent and selective corticotrophin-releasing factor(1) receptor antagonist. II. Characterization in rodent models of stress-related disorders. J Pharmacol Exp Ther 301:333-345.

Habib KE, Weld KP, Rice KC, Pushkas J, Champoux M, Listwak S, Webster
EL, Atkinson AJ, Schulkin J, Contoreggi C, Chrousos GP, McCann SM, Suomi SJ, Higley JD, Gold PW (2000) Oral administration of a corticotropin-releasing hormone receptor antagonist significantly attenuates behavioral, neuroendocrine, and autonomic responses to stress in primates. Proc Natl Acad Sci USA 97:6079-6084.

Hammack SE, Richey KJ, Schmid MJ, LoPresti ML, Watkins LR, Maier SF (2002) The role of corticotropin-releasing hormone in the dorsal raphe nucleus in mediating the behavioral consequences of uncontrollable stress. J Neurosci 22:1020-1026.

Heim C, Nemeroff CB (1999) The impact of early adverse experiences on brain systems involved in the pathophysiology of anxiety and affective disorders. Biol Psychiatry 46:1509-1522.

Holsboer F (1999) The rationale for corticotropin-releasing hormone receptor (CRH-R) antagonists to treat depression and anxiety. J Psychiatr Res 33:181-214.

Kawahara H, Kawahara Y, Westerink BH (2000) The role of afferents to the locus coeruleus in the handling stress-induced increase in the release of noradrenaline in the medial prefrontal cortex: a dual-probe microdialysis study in the rat brain. Eur J Pharmacol 387:279-286.

Kendler KS (1998) Gender differences in the genetic epidemiology of major depression. J Gend Specif Med 1:28-31.

Kirby LG, Rice KC, Valentino RJ (2000) Effects of corticotropin-releasing factor on neuronal activity in the serotonergic dorsal raphe nucleus. Neuropsychopharmacology 22:148-162.

Kishimoto T, Radulovic J, Radulovic M, Lin CR, Schrick C, Hooshmand F, Hermanson O, Rosenfeld MG, Spiess J (2000) Deletion of crhr2 reveals an anxiolytic role for corticotropin-releasing hormone receptor-2. Nat Genet 24:415-419.

Kornstein SG (1997) Gender differences in depression: implications for treatment. J Clin Psychiatry 58 [Suppl 15]:12-18.

Lechner SM, Curtis AL, Brons R, Valentino RJ (1997) Locus coeruleus activation by colon distention: role of corticotropin-releasing factor and excitatory amino acids. Brain Res 756:114-124.

Liotti M, Mayberg HS (2001) The role of functional neuroimaging in the neuropsychology of depression. J Clin Exp Neuropsychol 23:121-136.

Lucki I (1997) The forced swimming test as a model for core and component behavioral effects of antidepressant drugs. Behav Pharmacol 8:523-532.

Melia KR, Duman RS (1991) Involvement of corticotropin-releasing factor in chronic stress regulation of the brain noradrenergic system. Proc Natl Acad Sci USA 88:8382-8386.

Nemeroff CB (1988) The role of corticotropin-releasing factor in the pathogenesis of major depression. Pharmacopsychiatry 21:76-82.

Nemeroff CB (1992) New vistas in neuropeptide research in neuropsychiatry: focus on corticotropin-releasing factor. Neuropsychopharmacology 6:69-75.

Nestler EJ, Barrot M, DiLeone RJ, Eisch AJ, Gold SJ, Monteggia LM (2002) Neurobiology of depression. Neuron 34:13-25.

Penalva RG, Flachskamm C, Zimmermann S, Wurst W, Holsboer F, Reul JM, Linthorst AC (2002) Corticotropin-releasing hormone receptor type 1-deficiency enhances hippocampal serotonergic neurotransmission: an in vivo microdialysis study in mutant mice. Neuroscience 109:253-266.

Price ML, Lucki I (2001) Regulation of serotonin release in the lateral septum and striatum by corticotropin-releasing factor. J Neurosci 21:2833-2841.

Price ML, Curtis AL, Kirby LG, Valentino RJ, Lucki I (1998) Effects of corticotropin-releasing factor on brain serotonergic activity. Neuropsychopharmacology 18:492-502.

Reul JM, Holsboer F (2002) Corticotropin-releasing factor receptors 1 and 2 in anxiety and depression. Curr Opin Pharmacol 2:23-33.

Sauvage M, Steckler T (2001) Detection of corticotropin-releasing hormone receptor 1 immunoreactivity in cholinergic, dopaminergic and noradrenergic neurons of the murine basal forebrain and brainstem nuclei-potential implication for arousal and attention. Neuroscience 104:643-652.

Stenzel-Poore MP, Heinrichs SC, Rivest S, Koob GF, Vale WW (1994) Overproduction of corticotropin-releasing factor in transgenic mice: a genetic model of anxiogenic behavior. J Neurosci 14:2579-2584.

Swiergiel AH, Takahashi LK, Rubin WW, Kalin NH (1992) Antagonism of corticotropin-releasing factor receptors in the locus coeruleus attenuates shock-induced freezing in rats. Brain Res 587:263-268.

Valdez GR, Inoue K, Koob GF, Rivier J, Vale W, Zorrilla EP (2002) Human 
urocortin II: mild locomotor suppressive and delayed anxiolytic-like effects of a novel corticotropin-releasing factor related peptide. Brain Res 943:142-150.

Vale W, Spiess J, Rivier C, Rivier J (1981) Characterization of a 41-residue ovine hypothalamic peptide that stimulates secretion of corticotropin and beta-endorphin. Science 213:1394-1397.

Valentino RJ (1989) Corticotropin-releasing factor: putative neurotransmitter in the noradrenergic nucleus locus ceruleus. Psychopharmacol Bull 25:306-311.

Valentino RJ, Page M, Van Bockstaele E, Aston-Jones G (1992) Corticotropin-releasing factor innervation of the locus coeruleus region: distribution of fibers and sources of input. Neuroscience 48:689-705.

Valentino RJ, Liouterman L, Van Bockstaele EJ (2001) Evidence for regional heterogeneity in corticotropin-releasing factor interactions in the dorsal raphe nucleus. J Comp Neurol 435:450-463.

Webster EL, Lewis DB, Torpy DJ, Zachman EK, Rice KC, Chrousos GP (1996) In vivo and in vitro characterization of antalarmin, a nonpeptide corticotropin-releasing hormone $(\mathrm{CRH})$ receptor antagonist: suppression of pituitary ACTH release and peripheral inflammation. Endocrinology 137:5747-5750.

Young EA (1998) Sex differences and the HPA axis: implications for psychiatric disease. J Gend Specif Med 1:21-27.

Zobel AW, Nickel T, Kunzel HE, Ackl N, Sonntag A, Ising M, Holsboer F (2000) Effects of the high-affinity corticotropin-releasing hormone receptor 1 antagonist R121919 in major depression: the first 20 patients treated. J Psychiatr Res 34:171-181. 